\title{
Impact of Strategic Thinking on Achievement of Entrepreneurship in Al Manaseer Group (MG)
}

\author{
Feras $\mathrm{A} . \mathrm{Al} \mathrm{Zu}{ }^{\prime} \mathrm{bi}^{1}$ \\ ${ }^{1}$ Faculty of Finance \& Business, The World Islamic University for Science \& Education (WISE), Amman, \\ Jordan \\ Correspondence: Feras A. Al Zu’bi. E-mail: feras.alzubi@wise.edu.jo
}

Received: March 25, 2020

Accepted: April 7, $2020 \quad$ Online Published: April 30, 2020

doi:10.5539/ass.v16n5p82

URL: https://doi.org/10.5539/ass.v16n5p82

\begin{abstract}
One of the most critical abilities that entrepreneurs of today's business firms must have is strategic thinking (ST). Despite its role- rooted in full vision of entrepreneurial activities, especially the creation of new business projects, it has been ignored over the years in entrepreneurship (ENT) literature. This study seeks to explore if ST can promote ENT, and how with its dimensions - systems thinking (SsT), creative thinking (CT), and opportunism intelligence (OI), impacts the achievement of ENT in MG.

For research purposes, a questionnaire including 26 questions was conducted. First, reliability analysis was implemented to identify and eliminate irrelevant variables. Also, the researcher used Kolmogroph - Esmirnov test to consider the normality of variables' distribution. Finally, to analyze the impact of ST and its dimension on the achievement of ENT, simple and multiple linear regressions were performed. In light of results, ST and its components has a significant positive impact on ENT achievement. The OI was the most significant positive impact. This research provides a missing gap in strategic management studies enables us to have more actual view of entrepreneurs and ENT. Directions for further research are also suggested.
\end{abstract}

Keywords: thinking, strategic thinking, entrepreneurship, entrepreneurs

\section{Introduction}

Nowadays, like never before, the world witnessing several rapid changes and transformations of intellectual, political, economic, social, and in whole fields roughly. Thus, to move forward in all life aspects successfully and safely and encounter these changes, an extraordinary thinking is required and a distinctive style of multi-dimensional thinking skills that starts from extrapolating the past and present, be prepared for future, anticipating events, work to shape the features of potential virtual world, to align them with our ambitions to fulfill our short and long term goals.

This pattern of thinking is what has become known today as ST. We heard lots about terminology in which the word (strategic or strategy) as strategic war, ST, and strategic planning is mentioned, however we may not heard about strategic mind. Some may consider that ST, strategic mind, or even strategic planning is only the share of these prominent leaders those who carry massive responsibilities on their shoulders, but ST is in fact "a life principle" ensures safety and successfulness in reaching as well achieving and drawing roles.ST is rated as one of the most mainstays for building modern civilizations.

ST is a specific thinking approach, focused on addressing insight, and leading to an organizational integrated perspective through a synthetic process resulting from well use of intuition, creativity, systematic, opportunism, and innovation in shaping strategic directions (Oben Ürüa et al., 2011).

Moreover, ST makes us walk in safest and appropriate way, also enables us to take advantage of everything we need and all that we have, supports reaching the goal at lowest cost, fastest time, and the most proper way. Yet, many business organizations are increasingly encounter sophisticated issues, this requires a systematic, creative, and opportunism thinking to generate innovative solutions. Thus, building a dynamic business environment at the individual level and leaders in today's business companies through strategic thinking reflects positively on ENT and entrepreneurs alike.

For the past 3 decades, the ENT concept has come to the front in governmental policies deliberations, business community debates, scholars and researchers as well as planning academic programs. The growing interest in 
ENT in many countries of the world is partly due to national needs to encourage individuals to become more economically active in their societies, because of increasing pressure of global competition attributed to economic liberalization policies of governments to promote trade investment, and technology transfer (Bonn, 2001). Indeed, despite the fact that the concept of strategic thinking is already recognized (Bonn, 2005), it is a remarkable the reality that there is an imperative need for more studies that may assist us better understood, and its role in business ventures. This understanding will enable us to bridge the gap in strategic management research and a more comprehensive view of entrepreneurs and ENT alike.

For these and other reasons, scholars' interest in ST and ENT has been rekindled, and the subject matter has in recent years became a prominence, in sum, ST and ENT has become a very dynamic research area in different social science disciplines and a notable concern of economic policy. For these and other reasons, scholars' interest in ENT and ST has been rekindled, and the subject matter has in recent years come to prominence, in sum, ST and ENT has become a very dynamic research area in different social science disciplines and a notable concern of economic policy (Oben Ürüa et al., 2011; Katila et al., 2012; Al-Zu'bi \& Al-Nawasrah, 2017; Zahra \& Nambisan, 2011, 2012; Miloš, Lončar, 2017; Abraham, 2005; Alsaaty, 2007; Ghafarian \& Ahmadi, 2011; Isenberg, 2010; Mahdi et al., 2014; Bonn, 2001; Goldman, 2012).

Based on the above arguments, and in response to several recommendations for further research, an investigating in how can ST with its components: SsT, CT, OI impacts the achievement of ENT in MG worthwhile. The remainder of the research is structured as follows: Section 2 outlines the main theoretical framework; section 3 describes the extant literature review, Sections 4, 5 presesents the methodology and the results analysis and then conclude.

\subsection{Problem Statement}

Business firms in current era face intense and chaotic circumstances, competition, in addition to global economic and financial stagnation, the economic and political conditions that afflict the countries of the Middle East region, including Jordan. Thus, business firms are obliged to be equipped with ST tools, which are vital to evolve and survive in such chaotic events, and play a significant role economic growth and prosperity in modernistic world. (Nuntamanop et al., 2013, p. 243) stated that "in spite of a wide consensus on ST significance to business performance and ENT, an extensive literature review has found few studies that define what ST is or empirically verify how strategies and strategic actions business leaders in practice take relate to ST to achieve ENT." This statement was supported by many researchers (Abraham, 2005; Alsaaty, 2007; Antonic \& Hisrich, 2003; Churchill, 1992; F. Oben Ürüa et al., 2011; Stead \& Stead, 2013; Goldman, 2012; Casey \& Goldman, 2010; Nuntamanop et al., 2013; Bonn, $2001 \& 2005$ ).

The relationship between ST and ENT, still ambiguous. So, we should broaden our horizons and seize an opportunity to achieve ENT based on ST more than before. The privatization, globalization, acute competition, and ENT require strategic thinkers. However, from literature review, it is seen that there is lack of empirical research in general about the relationship between ST and ENT and in Jordan context in particular. Given the lack of academic studies about this topic, this research aims at investigating the impact of ST on achieving ENT in MG as one of the most vital economic sectors in supporting national economy and employment in Jordan.

\subsection{Research Significance}

Practical implications: The importance for practitioners is that the current study spotlight two vital constructs, ST and ENT also emphasized that ST for entrepreneurs leads to ENT.

Originality/value: This study explores some aspects of "thinking"- strategic mind - and its impact on ENT achievement that many researchers seem to have not focused on.

\section{Background}

\subsection{Thinking}

According to (De Bono, 1982), thinking is the last human resource that includes moving from a cognitive status to a better condition, also he added what occurs in the brain is information, the process it happens is thinking (De Bono, 1969). According to (Hayes, 1994), thinking involves ideas, possibilities, plans, and memory. As it is often called, brain is the human control center, regulates thinking and everything that a person does (Alsaaty, 2007). In the literature of management and social sciences, there are various references to different types of thinking including critical, inductive, deductive, and systematic and ST (Dunbar \& Fugelsang, 2012).

However, over the years, thinking has been described with multiple names, and categorized into two kinds: vertical thinking and ST (Alsaaty, 2007), vertical thinking means logical, mathematical, analytical and rational 
thinking (Hayes, 1994). In spite of the fact that each of these thinking kinds might be deemed a certain thinking manner, but it is not easy to determine its locations, as its borders are fictitious and interrelated(Al Saaty,2007), however, in fact, it can be argued that, the concept of these terms are on the whole are analogous. (Hussey, 2001) indicated that there is no solid sequence to whether smart ideas precede or follow the analytical activities.

Vertical thinking is sequent, disciplined, and rule-based, and in it an individual moves in the thinking process forward by sequential steps, each must be justified (De Bono, 1970). ST as the main subject of the current research will be discussed in detail in the next section. As experts and scientists reveal, brain is divided into two hemispheres (Pink, 2006): the left- hemisphere (performs vertical thinking), and the right - hemisphere (performs ST), and both brain halves complement each other and are critical to a healthy human performance, although the power of left-brain is necessary, but it is not enough, it should be promoted with right- brain capabilities. In this research, the position taken is that successful entrepreneurs are strategic thinkers, that is, they are very inclined to take advantage of the power of the right hemisphere more than other humans. Moreover, individuals with commercial brains with ST skills are more likely to become entrepreneurs and obtain the ENT and more successful in the long run.

\section{$2.2 S T$}

According to (Allio, 2006), ST initiated to prosper in 1960s and receive momentum by 1990. (Lin et al., 2008), stated that strategic planning began in 1950s, and then shifted the focus from strategic planning to strategic management, and now to ST. ST is to identify the features of competitions and current invisible opportunities (Ghafarian \& Ahmadi, 2011). (Skrt \& Antonic, 2004, p. 107) note that ST has become a must for all entrepreneurs to sustain ENT in the time of global competition, technological change and increased dynamics in markets.

According (Bonn, 2005; Marcelo, 2017), some authors have utilized the notion of ST from other views as strategic planning and management, e.g., Wilson states: "trying to develop organizational status changes the base of strategic planning so that we should consider it as strategic management or strategic thinking" (Sarhangi, 2011).There is no general agreement about the meaning of ST in literature of strategic management due to a problem in expressing the cognitive its nature, it is very difficult to allocate, to measure, train, or learn. Literature defines ST widely as key component of strategy development, a mental, and reflective and an issue oriented process that aims to develop new strategies and that may happen before, during or after strategic planning (Goldman, 2012; Liedtka, 1998; Marcelo, 2017).

ST is: "a distinct form of pragmatic reasoning (Larson \& Hansen, 2005, p. 1); along process and its goal are to solve ambiguity and complex environment signify (Bonn, 2005); reveal credible strategies or business paradigms leading to build values for customers (Abraham, 2005); a sensible ideas, thoughtful analyses, and sound decisions (Alsaaty, 2006, p. 26); creating something out of nothing - willful thinking to accomplish something unique, and creating a new business project (Alsaaty, 2007); a top management activities that aim to detect new and creative strategies to rewrite competition standards, and innovated future potencies that is completely unlike the exist form (Goldman, 2007); a process in which an individual perceives, reflecting, feeling, realizing and acknowledging signs that effect the organization's future, giving them meaning and acting upon them by shaping the impressions, perspective and behavior accordingly (Jelenc, 2009); explore competition features as well as current invisible opportunities (Ghafarian \& Ahmadi, 2011).

In strategic management literature, several (components / skills/ characteristics) of dimensions of ST are mentioned, each according to its research objective. In this research SsT, CT \& OI are adopted as a basis because it is the most cited in theoretical studies, as shown in Table 1

Table 1. ST dimensions

\begin{tabular}{ll}
\hline Author(s) & ST elements /characteristics/skills \\
\hline $\begin{array}{l}\text { Bonn, 2001, 2005; Goldman, 2005, 2012, 2015; AJa'faryani, 2011; } \\
\text { Rezvanpour, Mitabah, \& Sahay, 2004 }\end{array}$ & $\begin{array}{l}\text { Systems thinking, creativity, opportunism } \\
\text { intelligence. }\end{array}$ \\
Liedtka, 1998, 2000; Bonn, 2001, 2005; Stead \& Stead, 2013 & Systems perspective, intelligent opportunism. \\
Glamour, 2010, Goldman, 2005, 2007; Al-Zu'bi \& Al-Nawasrah, 2017 & Creative thinking, complex or systems thinking. \\
Sloan, 2013; Arayesh \& Golmohammadi, 2011 & Creative, opportunism intelligence. \\
Pisapia, 2009; Abraham, 2005; Bower \& Gilbert, 2007 & Systems thinking, creative thinking \\
Pisapia et al. 2005; Karğin \& Aktas, 2012; Stead \& Stead, 2013 & Systems thinking, opportunism intelligence. \\
\hline
\end{tabular}




\section{$2.3 E N T$}

ENT is in its early stage of development like other social sciences, is open to varying views and explanations as a body of knowledge (Alsaaty, 2007; Antonic \& Hisrich, 2003). A number of scholars trace the origin of ENT to economic theory throughout the $18^{\text {th }}$ Century, (Salem, 2005; Churchill, 1992)) indicated that 1730 was the thrilling event of the emergence of the ENT domain, according to him, the first to place the ENT function in the field of economics is Cantillon. Also, (Formaini, 2006; Oben Ürüa et al., 2011), indicated that Cantillon was the most known Physiocrats whose research contribution introduced the concept of entrepreneur into economic analysis.

The list of prominent contributors in this field (Alsaaty, 2007; Hisrich, 2011) has grown to include for instance (Joseph Schumpeter -1883-1950), and (Peter Drucker - 1909-2005) over the time. ENT despite its economic roots is considered a complex and multidimensional field and relied on specializations such as sociology, ecology, and psychology, and economics as well (Yetisen et al., 2015). A wider definition of the term ENT is utilized, particularly in economic area (Alvarez et al., 2006).

Today, ENT evolution has become very worthy of attention; in view of its being a corner stone in economic growth (Churchill, 1992; Salim, 2005; Zahra \& Nambisan, 2011). The objectives of evolution, regional growth, and employment generation depend upon entrepreneurial development (Antonic \& Hisrich, 2003; Zahra \& Nambisan, 2012). ENT is the process of launching, designing and managing new business, which is mostly to start with small firm; individuals who founded these firms are called entrepreneurs (AK Yetisen et al., 2015).

According to (Hisrich \& Robert, 2011), describe ENT as the "ability and wish to evolve, regulate and manage a business project with risk taking to produce a profit (Katila et al., 2012). ENT is a process of actions of an entrepreneur who is a person always in search of something new and exploits such ideas into gainful opportunities by accepting the risk and uncertainty with the enterprise (Ghafarian \& Ahmadi, 2011; Shah \& Tripsas, 2007).

Frequently, definitions of ENT focused on launching and managing a business, taking the high risks into account involved for instance, lack of financing and market demand, bad business decisions, economic crisis, and the absence of ST, or a combination of all of these (Katila et al., 2012; Zahra \& Satish Nambisan, 2012). ENT in this research regardless of its origins and historical development is seen as a variable that can be affected by ST and its components (SsT, CT, and OI), and an attempt to measure the level of ST among managers and executives in MG which consists of (23) company and institution in various service and industrial fields in Jordan and abroad.

\subsection{Importance of ST for Entrepreneurs \& ENT}

ST is a value for all humankind, as it is necessary for individuals who want to become a successful entrepreneur, ST is motivated and meditative. ST empowers entrepreneurs to navigate trusty in a competitive and dynamic environment, and it is recognized by multiple thinking skills such as SsT, CT and OI well. In this regard, the entrepreneur is a person that has the capacity to create and take action upon opportunities to convert inventions or technologies into products or services, "the entrepreneur is eligible to meet the commercial potential of the invention and organize the capital, talent, and other assets that turn an invention into a commercially fertile innovation, in this sense, the term "ENT" also seize innovative business on the side of established firms, and similar activities on the aspect of new businesses.

Moreover, ST can help entrepreneurs in other domains, containing the following: results managing, taking reasonable business decisions, get ready for future; seeing events in a more holistic manner; threats anticipation; challenging problem solving; understanding environmental trends; Seizeing opportunities; (Katila et al., 2012) determining the market needs for the intended projects and business; collect and exploit appropriate resources; positioning the venture for success; avoiding extravagant risks; building alliances (Yetisen et al., 2015).

In both developing and developed countries, it is vastly recognized that entrepreneurs are the engine of economic growth and development (Farsi et al., 2012; Zahra, 2008). Therefore, the term entrepreneurs were defined by (Kruger \& Brazeal, 1994; Zahra \& Nambisan, 2011), they are individuals who think systematically, creatively, and seek to seize opportunities intelligently. It is noted from the previous definition that ENT and entrepreneurs are think systematically, creatively and opportunistically, (and they should be) to achieve their business aims.

Entrepreneurs are the seeds of economic growth, and the fruits of industrial development that are greater employment opportunities to unemployed youth, increase in per capita income, higher standard of living and increased individual saving, revenue to the government in the form of income tax, sales tax, export duties, import duties, and balanced national development. The common influences of these advantages of ST on entrepreneur's willingness to identify, evaluate, and conduct a business projects is bound to be valuable, (Zahra \& Nambisan, 
2011) because the absolute ST skills, including (SsT, CT, and OI), supplies businessmen with justifications and encourage them involved in making decisions to seize the opportunity(s), or refrain from wanting to work for compelling reasons.

Exploiting, creating, shaping, and navigating business ecosystems need entrepreneurial insight, integrated with ST (Zahra\& Nambisan, 2012). This thinking is evident in the newness and speed of strategic actions, and creativity in the use and well exploitation of resources, as this thinking is reflected in the creation of a new company or project that is able to adapt and transform according to the business environment and, and shift of competition forces. Such an organization/ project will be capable to create and find out opportunities in simultaneous with seizing other opportunities creatively and profitably as well. Competing in economic systems requires; the coincidence of ST and ENT, a process that further creates new knowledge supporting entrepreneurial activities and ST (Iansiti \& Levien, 2004; Nambisan \& Sawhney, 2007).

\section{Literature Review}

The notion of ST has been highly recognized in the arena of strategic management and in a great number of researches it's been referred to as a key attribute for entrepreneurs and ENT (Johnson, Scholes \& Wittington, 2010). (Goldman, Scott, \& Follman, 2015, p. 155) stated that "there is extrnsive consensus that ST is important for the direction and organizations sustainability, and ENT achievement, but is often absent or at least quite few. The inability of business leaders to think strategically negatively affects economic performance, excellence, and the achievement of ENT (Goldman, 2012). Creating and seizing the opportunity (Nuntamanop et al., 2013) thinking systematically and creatively are some of the main tasks of entrepreneurs.

Many previous studies have confirmed that ST is an individual thinking activity that benefits business and projects, purposes to discover competitive strategies to position projects significantly differently from the present (Bower \& Gilbert, 2007; Casey \& Goldman, 2010; Goldman, 2012; Reeves et al., 2015). ST (Nuntamanop et al., 2013; Pretorius, 2008; Stead \& Stead, 2013) is SsT, CT, and OI that contributes to broad, general, overarching concepts that focuses on future direction of an organization based on anticipated political, economic, and environmental conditions, and achievement of ENT.

(Goldman 2012, p. 26) finds out that "at the same time the gap at the top management is recognized, so is the need to evolve the ST capacity of those at deeper levels in business firms, also he added that, the nature of nowadays business environments oblique individuals to interpret sophisticated information and evolve strategies and thinking strategically that improve organizational routines and processes. (Bonn, 2001), in a study with 35 out of 100 greatest manufacturing firms in Australia in 1993, found out through interviews with senior executives responsible for strategic planning, strategic management or corporate development that "the major issue specified by the majority of senior executives was ST,the results of her study showed that" individual members, in particular senior managers, should have a holistic grasping of an organization and its environment, they should be creative, and they should possess future vision for their organizations.

(Zahra \& Nambisan, 2012) explored the dynamic interplay between ENT and ST in different types of business economic systems and how that interaction influences the ways firms compete. ST has many interrelated characteristics, containing a systemic and creative thinking, which in turn impacts ENT (Abraham, 2005; Lidtka, 1998). ST requires work in with a future assumed competitive and integrating point views of varying perceptions into a total coherent( Stead, \& Stead, 2013), this integration requires creativity; also ST is also systemic in that it builds on the linkages between various components that form a vision for the ENT future (Liedtka, 2000; Bonn \& Fisher, 2011).

The ENT requires strategically thinking skills such as creative, systematic, and opportunism that in changing the competitive arena, and promotes ENT (Isenberg, 2010). For an organization's successfulness, according to (Kabacoff, 2013) reported in his study in which $(97 \%)$ of a group of $(10,000)$ senior executives that ST is the most critical leadership skills. In another study, 60,000 managers and executives in more than (140) countries rated a ST to leadership as more effective than other attributes including communication, innovation, persuasion, and results guidance (Kabacoff, 2013). Organizations core competencies are strategic thinking, and rely on it for conducting business for long - term. Successful strategic thinkers have a holistic vision of their business and remain intelligently opportunistic on their capability to solve future problems (Lidtka, 1998; Goldman, Scott \& Follman, 2015).

According to Lidtka, a strategic thinker must have a mental model to fully understand the relationship between its various components and activates (Lidtka, 2000). SsT represents a holistic approach to entrepreneurship, thus, successful entrepreneurs have the capability to perceive the world as a system (Goldman, 2012). For entrepreneurs, CT is an important advantage, as it is a skill that can be learned and thus taught. To achieve ENT, 
entrepreneurs must give the CT in the center role that it deserves. The path to ENT usually starts with a clear motivation to become an entrepreneur and an idea for a new good or service that will appeal to an identified market (Peterman \& Kennedy, 2017). OI is about adopting a flexible approach to strategy in order to take advantage of emerging strategies and new opportunities and, by being 'intelligently opportunistic', entrepreneurial leaders can influence strategic decision making (Haycock, 2012), in ST, managers must embrace new ideas all the time.

\section{Methodology}

\subsection{Research Framework}

This framework proposes that ENT is affected by ST and its dimensions SsT, CT and OI. Thence, the variable of major interest is the ENT which is the dependent variable, while ST (SsT, OT, and OI) are the independent variables. Research framework is depicted in Figure 1 followed by research hypotheses.

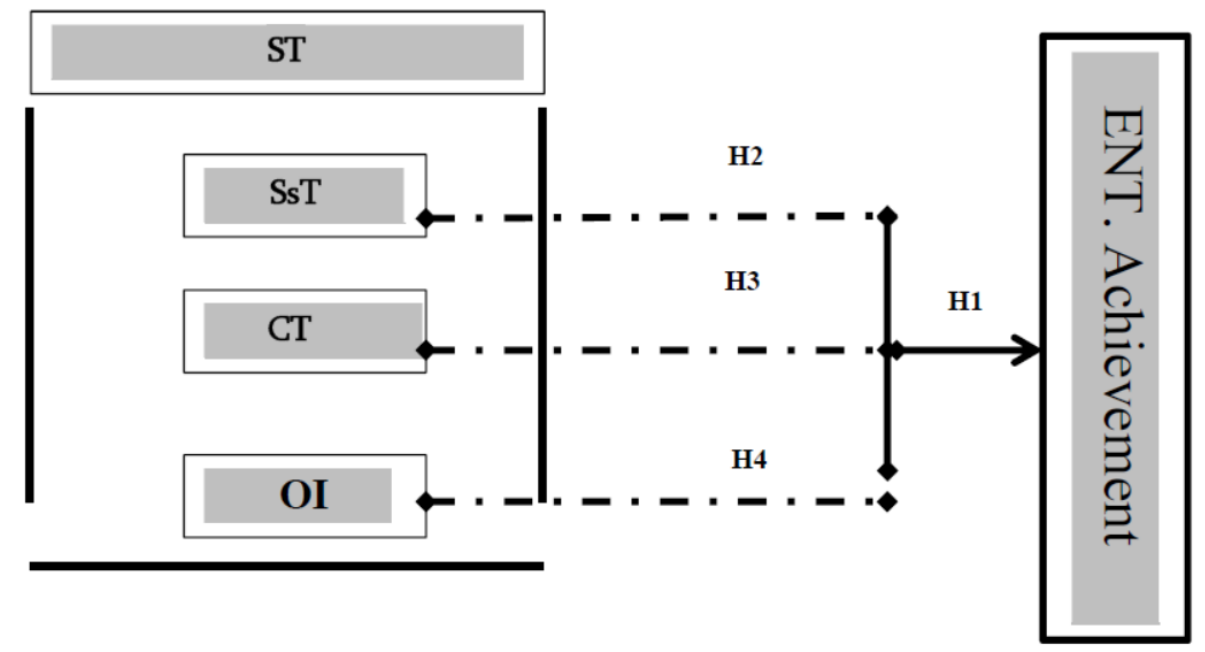

Figure 1. Research framework

\subsection{Research Hypotheses}

Based on the above research framework and literature, so the following hypotheses are proposed as follows:

H1: ST has a significant positive impact on ENT achievement.

H2: SsT has a significant positive impact on ENT achievement.

H3: CT has a significant positive impact on ENT achievement.

H4: OI has a significant positive impact on ENT achievement.

\subsection{Research Operational Definitions of Variables \& Measurements}

This research is foremost based on previous literature in this field. The variables were carefully chosen and defined in order to achieve the research objectives and benefit from its importance. Moreover, taking into account the willingness to fill questionnaire, the number of statements was reduced as far as possible. Regarding statements formulate, 5 point - Likert scale is utilized. The variables operational definitions are as follows:

(1) ST- Independent variable - is based on many different researchers' studies like (Johnson, Scholes \& Wittington, 2010; Goldman, Scott, \& Follman, 2015, p. 155; Liedtka, 2000; Amitabah \& Sahay, 2004; Karğin \& Aktas, 2012; Mahdi Mahdaviana et al., 2014; Goldman, 2005; Ja'faryani, 2011; Rezvanpour, 2012; Moon, 2013; Matheson \& Matheson, 2011; Al- Ta'e et al., 2013) for exploration, dividing ST into 3 variables: SsT,CT \& OI, with total 18 questions.

(2) ENT Achieving: dependent variable, as for evaluation of achieving this variable the views of (Oben Ürüa et al., 2011; Ivanova \& Gibcus, 2003; Li et al., 2013; Miloš Lončar, 2017; Zahra \& Nambisan, 2011) are used as the foundation with total 8 questions.

\subsection{Research Population \& Sampling}

The research population of this study includes MG that working in various fields of services and production. According to the statistical data available on MG website, there are currently around 23 companies in addition to 
partnerships with entrepreneurial firms in Jordan, and it employs nearly 10,000 employees in Jordan with investments up to 2 billion. Source. Manaseer Group / Home: https://www.manaseergroup.com/. A survey method was used as research methodology and questionnaires as tool to collect data to investigate the effect of ST on achieving ENT on MG, moreover exploring variables' correlations. This study uses the intentional random sampling technique from among sampling methods. In terms of data research, the sample uses on-site survey and online questionnaires, and a questionnaire subjects are primarily executives, general directors, and operations managers.

\subsection{Samples}

After draft of questionnaire ending, 7 managers are invited to participate in pre-test activities related to questionnaire. The purpose of this is that they can review items that may be difficult or confusing to realize, so they can be modified or delete some items in order to minimize the difficulties that the respondents may face when filling out the questionnaire, the final version was applied as well as empirical analysis. In terms of data gathering, a part of samples in this study use on-site surveys $(30 \%)$, another parts is conducted utilizing online questionnaires - by e- mail (70\%). 67 out of 69 questionnaires were returned, 6 invalid are neglected, so there are 61 valid samples with response rate of $88.4 \%$.

\subsection{Validity \& Reliability}

To ensure validity, feedback was solicited from several professors in Jordanian universities in multiple disciplines such as (business administration, strategic planning and marketing), as well as 4 managers in MG who are asked to fill them out, thus, the degree of validity is high. With respect to reliability, this research utilizes item analysis to verify and remove variables which were irrelevant to research construct, and uses main constructs analysis to calculate the Cronbach's a value illustrated in Table 2, which are all exceeds than (0.7), consequently there is considerable reliability.

Table 2. Reliability analysis

\begin{tabular}{cccccc}
\hline Variable & ST & SsT & CT & OI & ENT \\
\hline A & 86.3 & 82.8 & 81.7 & 79.9 & 86.9 \\
\hline
\end{tabular}

\section{Research Results Analysis}

To analyze the impact of ST and ST components (SsT, CT \& OI) on ENT, Multiple and simple linear regression to test the hypotheses were performed. In addition, the researchers used - Kolmogorov - Smirnov - test to consider the normality of variables' distribution. The test revealed variables homogeneity with a normal distribution.

Testing Hypotheses Using Regression Analysis

\section{H1: ST has a significant positive impact on ENT achievement}

As revealed in Table 3, results of analysis show that the coefficients ST, CT, OI reached a significant impact $(\alpha=$ $0.000,0.024)$, which means that there is a significant linear correlation $(\mathrm{R}=0.856)$ between ST, CT, and OI and ENT, which also means that ST, CT \& OI together has a significant positive impact on ENT achievement ENT, while, SsT is not ( sig.t $=0.111$ ). Thus, H1 is supported.

Table 3. Regression analysis of ST to ENT achievement

\begin{tabular}{|c|c|c|c|c|c|c|c|c|c|c|c|}
\hline \multirow{2}{*}{ H1 } & \multirow{2}{*}{ ST } & $\mathrm{R}$ & $\mathrm{R}^{2}$ & $\mathrm{~F}$ & D.F & Sig. F & ENT & B & \multicolumn{2}{|c|}{ Std.Error T } & Sig. $t$ \\
\hline & & $\overline{0.856}$ & 0.733 & 235.877 & 3 & $0.000^{*}$ & SsT & 1.739 & .1680 & 1.599 & $0.111^{*}$ \\
\hline \multirow{2}{*}{\multicolumn{3}{|c|}{$*$ Sig. level $<0.05$}} & & & & & CT & 0.040 & 0.091 & 2.269 & $0.024 *$ \\
\hline & & & & & & & OI & 0.047 & 0.603 & 12.969 & $0.000 *$ \\
\hline
\end{tabular}

\section{H2: SsT has a significant positive impact on ENT achievement}

The results of analysis show that Table 4, SsT also reaches significant levels, which means SsT has a significant positive impact $[\mathrm{R}=0.822$; sig.F $=0.000$; sig.t $=0.022]$ on the ENT achievement; consequently, $\mathrm{H} 2$ is also supported. 
Table 4. Regression analysis of SsT to ENT achievement

\begin{tabular}{|c|c|c|c|c|c|c|c|c|c|c|}
\hline \multirow{2}{*}{$\mathrm{H} 2$} & \multirow{2}{*}{ SsT } & $\mathrm{R}$ & $\mathrm{R}^{2}$ & $\mathrm{~F}$ & D.F & & B & Std.Error & $\mathrm{T}$ & Sig. $\mathrm{t}$ \\
\hline & & 0.822 & 0.676 & 179.472 & 1 & $0.000^{*} \mathrm{ENT}$ & 0.643 & 0.047 & 13.681 & $0.022^{*}$ \\
\hline
\end{tabular}

*Sig.level $<0.05$

\section{H3: CT has a significant positive impact on ENT achievement}

Results from Table 5, show that $\mathrm{CT}$ also reaches significant levels, which means $\mathrm{CT}$ has a significant positive impact $[\mathrm{R}=0.801$; sig.F $=0.000$; sig.t $=0.002]$ on the ENT achievement; consequently, $\mathrm{H} 3$ is also supported.

Table 5. Regression analysis of CT to ENT achievement

\begin{tabular}{|c|c|c|c|c|c|c|c|c|c|c|c|}
\hline \multirow{2}{*}{ H3 } & \multirow{2}{*}{ CT } & $\mathrm{R}$ & $\mathrm{R}^{2}$ & $F$ & D.F & Sig F & \multirow{2}{*}{ ENT } & B & Std.Error & $\mathrm{T}$ & Sig t \\
\hline & & 0.801 & 0.641 & 153.613 & 1 & $0.000^{*}$ & & 0.595 & 0.048 & 12.394 & $0.002^{*}$ \\
\hline
\end{tabular}

$*$ Sig.level $<0.05$

\section{H4: OI has a significant positive impact on ENT achievement}

Results from Table 6, indicates that OI also reaches significant levels, which means OI has a significant positive impact on the ENT achievement $[\mathrm{R}=0.818$; sig.F $=0.000$; sig.t $=0.000]$ consequently, $\mathrm{H} 4$ is also supported as well.

Table 6. Regression analysis of OI to ENT achievement

\begin{tabular}{|c|c|c|c|c|c|c|c|c|c|c|c|}
\hline \multirow{2}{*}{$\mathrm{H} 4$} & \multirow{2}{*}{ OI } & $\mathrm{R}$ & $\mathrm{R}^{2}$ & $\mathrm{~F}$ & D.F & Sig F & \multirow{2}{*}{ ENT } & B & Std.Error & $\mathrm{T}$ & Sig t \\
\hline & & 0.818 & 0.668 & 173.279 & 0.000 & $0.000 *$ & & 0.777 & 0.059 & 13.163 & $0.000^{*}$ \\
\hline
\end{tabular}

$*$ Sig.level $<0.05$

\section{Conclusions}

This study explored the correlation of variables ST, SsT, CT, IO, and ENT in MG. Based on the results of empirical analysis, this section argues the fundamental findings and important implications. In multiple regression analysis, results show that achieving ENT is influenced by ST, and the two variables CT, and OI, but it is not affected by SsT. Thus, ST has a significant positive impact on ENT achievement in MG, which is consistent with the views of (Zahra \& Nambisan, 2011; Oben Ürüa et al., 2011; Nuntamanop et al., 2013; Goldman, Scott, \& Follman, 2015; Stead \& Stead, 2013; Reeves et al., 2015).

Moreover, in simple regression analysis, in terms of the impact of SsT on achieving ENT in MG, result of H2 indicated that SsT has a positive significant impact on achieving the ENT in MG. This result was supported by (Bonn, 2001 \& 2005; Liedtka, 2000; Goldman, 2012). This means that strategic thinker must have a mental paradigm to comprehensive understand the relationship between businesses various components. Thinking systematically and holistically intelligently leads to ENT achievement.

In terms of CT and ENT achievement (H3), CT has a positive significant impact on ENT achievement, this is consistent with (Peterman \& Kennedy, 2017; Ward, 2004). This assures that proactive firms are related to their entrepreneurs' ability to creative to fulfill ENT. Therefore, CT is seen as a precondition for achieving ENT, and therefore individuals who are creatively thinking are more likely to access ENT.

In terms of OI and ENT achievement (H4), results of simple and multiple regression analysis indicated that OI has the highest impact in achieving ENT among other ST dimensions. This is consistent with (Goldman, 2005; Haycock, 2012; Liedtka, 1998; Zahra, \& Nambisan, 2011; Bonn, 2001; Peterman \& Kennedy, 2017; Ward, 2004; Alsaaty, 2007). This result is expected, as strategic thinkers and entrepreneurs are looking for new opportunities in their ventures. OI refers to a new idea, new product / service, and allowing entrepreneurs to seize the opportunity and gain advantage.

Also involves the entrepreneurs being open-minded to new skills and experiences that allow them to take 
advantage of emergent strategies that are more relevant in a rapidly changing business environment and can be considered a form of 'opportunistic' strategy (Liedtka, 1998). ST affects ENT by embracing executive management a new ideas, and developing spaces for strategic options to reach ENT. In ST, creating an opportunities is regarded as the basic principle, thus, business firms have to embrace new experiences in order to harness strategic thinking options in business environment and its entrepreneurial.

In terms of overall results, empirical research results of regression analysis show that, ST has a significant impact on ENT achievement .In multiple regressions, OI is the most influential variable on ENT achievement followed by CT, while SsT has no any significant effect. In simple regression, OI is also has the highest impact on ENT achievement, followed by SsT, and then CT. To complete this study, the researcher suggests conducting: - a similar study in other context;- investigating the impact of other ST elements on ENT such as future vision, political sensitivity, intuition, uncertainty. In sum, directing ventures through ST towards ENT achievement is vital in today's changing environment. All of these perspectives must be addressed in greater depth to fulfill ENT and continue with further research.

\section{References}

Abraham, S. (2005). Stretching strategic thinking. Strategy \& Leadership, 33(5), 5-12. https://doi.org/10.1108/10878570510616834

Agarwal, R., Audretsch, D., \& Sarkar, M. B. (2007). The Process of creative construction: knowledge spillovers, entrepreneurship and economic growth. Strategic Entrepreneurship Journal, 1(2), 263-286. https://doi.org/10.1002/sej.36

Allio, R. (2006). Strategic thinking: The big ten ideas. Strategy \& Leadership, 34(4), 4-13. https://doi.org/10.1108/10878570610676837

Alsaaty, F. M. (2007). Entrepreneurs: Strategic Thinkers in Search of Opportunities. Journal of Business \& Economics Research, 5(2), 66-71. https://doi.org/10.19030/jber.v5i2.2523

Alvarez, S., Ireland, R., \& Reuer, J. (2006). Entrepreneurship and strategic alliances. Journal of Business Venturing, 21(4), 401-404. https://doi.org/10.1016/j.jbusvent.2005.03.001

Al-Zu'bi, H. A., \& Al-Nawasrah, M. S. (2017). Analyzing the Impact of Strategic Thinking Competencies in Building Intelligent Organization. International Journal of Academic Research in Business and Social Sciences, 7(7), 356 -365. https://doi.org/10.6007/IJARBSS/v7-i7/3107

Antonic, B., \& Hisrich, R. D. (2003). Clarifying the intrapreneurship concept. Journal of Small Business and Enterprise Development, 10(1), 7-24. https://doi.org/10.1108/14626000310461187

Audretsch, D. B., Bozeman, B., Combs, K. L., Feldman, M., Link, A. N., Siegel, D. S., ... Wessner, C. (2002). The Economics of Science and Technology. The Journal of Technology Transfer, 27(2), 157. https://doi.org/10.1023/A:1014382532639

Bonn, I. (2001). Developing strategic thinking as a core competency. Management Decision, 39, 63-71. https://doi.org/10.1108/EUM0000000005408

Bonn, I. (2005). Improving strategic thinking: A multilevel approach. Leadership \& Organizational Development Journal, 26, 336-354. https://doi.org/10.1108/01437730510607844

Bonn, I., \& Fisher, J. (2011). Sustainability: The missing ingredient in strategy. Journal of Business Strategy. https://doi.org/10.1108/02756661111100274

Bower, J. L., \& Gilbert, C. G. (2007). Create or Destroy Your Company's Strategy. Harvard Business Review, (February 2007).

Casey, A. J., \& Goldman, E. F. (2010). Enhancing the ability to think strategically: A learning model. Management Learning. https://doi.org/10.1177/1350507609355497

Churchill, N. C. (1992). Research issues in entrepreneurship. In D. L. Sexton, \& J. D. Kasarda (Eds.), The State of Art of entrepreneurship (pp. 579-596). PWS - KENT, Boston, MA. https://doi.org/10.1046/j.1540-6520.2003.00035.x

De Bono, E. (1969). The Mechanism of the Mind. New York: Simon \& Schuster. 11.

De Bono, E. (1970). Lateral Thinking. New York: Harper \& Row, Publishers.

De Bono, E. (1982). de Bono Thinking Course. New York: Facts on File Publications.

De Bono, E. (1984). Tactics: The Art and Science of Business. Boston; Little, Brown and Company. 
Dunbar, K. N., \& Klahr, D. (2012). Scientific thinking and reasoning. In K. J. Holyoak, \& R. G. Morrison (Eds.), The Oxford handbook of thinking and reasoning (pp. 701-718). New York: Oxford University Press. https://doi.org/10.1093/oxfordhb/9780199734689.013.0035

Formaini, R. L. (2006). The Engine of Capitalist Process: Entrepreneurs in Economic Theory. In R. W. Price (Ed.), Entrepreneurship, Dubuque: IA, McGraw-Hill Dushkin (p. 3).

Ghafarian, V., \& Ahmadi, A. (2011). Strategic thinking. Electronic Reference Management Science in Iran, 3(2), 274.

Goldman, E. F. (2012). Leadership practices that encourage strategic thinking. Journal of Strategy and Management. https://doi.org/10.1108/17554251211200437

Goldman, E. F., Scott, A. R., \& Follman, J. M. (2015). Organizational practices to develop strategic thinking. Journal of Strategy and Management, 8(2), 155. https://doi.org/10.1108/JSMA-01-2015-0003

Hamel, G., \& Prahalad, C. K. (1989). Strategic intent. Harvard Business Review, 70(3), 63-78.

Haycock, K. (2012). Strategic thinking and leadership. Library Leadership and Management, 26(3-4), 1- 23.

Hisrich, R. D. (2011). Entrepreneurship. McGraw-Hill Education. ISBN 978-0-07062-017-9.

Oben Ürüa, F., Sezer, C., Çalıúkana, Ö. A., \& Aksua, M. (2011). How Much Entrepreneurial Characteristics Matter in Strategic Decision-Making? International Strategic Management Conference 7th.

Stead, J. G., \& Stead, W. E. (2013). The Coevolution of Sustainable Strategic Management in the Global Marketplace. Organization \& Environment, 26(2), 162-183. https://doi.org/10.1177/1086026613489138

Ward, T. B. (2004). Cognition, creativity, and entrepreneurship. Journal of Business Venturing, 19, 173-188. https://doi.org/10.1016/S0883-9026(03)00005-3

Yetisen, A. K., Volpatti, L. R., Coskun, A. F., Cho, S., Kamrani, E., Butt, H., ... Yun, S. H. (2015). "Entrepreneurship". Lab Chip., 15(18), 3638-3660. https://doi.org/10.1039/C5LC00577A

Zahra, S. A. (2008). The virtuous cycle of discovery and creation of entrepreneurial opportunities. Strategic Entrepreneurship Journal, 2(3), 243-257. https://doi.org/10.1002/sej.47

Zahra, S., \& Nambisan, S. (2011). Entrepreneurship in global innovation networks. AMS Review, 1(1), 4-17. https://doi.org/10.1007/s13162-011-0004-3

Zahra, S., \& Nambisan, S. (2012). Entrepreneurship and strategic thinking in business ecosystems. Business, 55(3), 219-229. https://doi.org/10.1016/j.bushor.2011.12.004

\section{Copyrights}

Copyright for this article is retained by the author(s), with first publication rights granted to the journal.

This is an open-access article distributed under the terms and conditions of the Creative Commons Attribution license (http://creativecommons.org/licenses/by/4.0/). 